\title{
Glycaemic indices and glycaemic loads of common Korean carbohydrate-rich foods
}

\author{
Do-Yeon $\mathrm{Kim}^{1}$, Yeajee $\mathrm{Kim}^{2}$ and Hyunjung $\mathrm{Lim}^{1,2 *}$ \\ ${ }^{1}$ Research Institute of Medical Nutrition, Kyung Hee University, Seoul 02447, Republic of Korea \\ ${ }^{2}$ Department of Medical Nutrition, Graduate School of East-West Medical Science, Kyung Hee University, Yong-in 17104, \\ Republic of Korea
}

(Submitted 15 July 2018 - Final revision received 17 October 2018 - Accepted 5 November 2018 - First published online 27 December 2018)

\section{Abstract}

Glycaemic index (GI) and glycaemic load (GL) values of foods consumed in Asia remain poorly characterised despite the fact that Asian diets are high in carbohydrates. We evaluated the GI and GL of the most commonly consumed carbohydrate-rich foods, according to food type and cooking methods. GI and GL values were determined using protocols from the FAO/WHO and International Standards Organization recommendations. A total of 152 healthy subjects were enrolled in the study. In all, forty-nine carbohydrate-rich foods were categorised as cereal grains, noodles and pasta, breads and other processed grains and starchy vegetables, prepared using standard cooking methods and evaluated. Cereal grains had the widest range of GI values that the food made with white rice and barley had GI values of 51-93 and 35-70, respectively, according to cooking methods, and most cereal grains had high GL values. Noodles and pasta had low to medium GI values, but most foods had high GL values. Breads had medium to high GI and GL values, while other processed grains had low to medium GI and GL values. The GI values for food made with starchy vegetables (e.g. potatoes and sweet potatoes) varied widely for different cooking methods but tended to have low GL values. In conclusion, GI values for a single food type varied widely with the cooking method used. This study of GI and GL values for common carbohydrate-rich foods provides a valuable reference for consumers and health professionals to make informed food choices for glycaemic control.

\section{Key words: Glycaemic index: Glycaemic load: Carbohydrate-rich foods: Cooking methods}

Glycaemic index (GI) values have been widely used and endorsed by the FAO and WHO for guiding food choices ${ }^{(1)}$. The GI metric was introduced to classify carbohydratecontaining foods systematically according to their ability to produce a postprandial glycaemic response ${ }^{(2,3)}$. Carbohydrates in foods with lower GI values are digested and absorbed more slowly and consequently have a lower impact on blood glu$\operatorname{cose}^{(4)}$. Low-GI foods increase insulin sensitivity ${ }^{(4)}$ and are the preferred choice for glycaemic control ${ }^{(5)}$. High-GI diets are associated with higher insulin levels and increased risk of diabetes $^{(4)}$. Mechanistically, high-GI foods may stimulate insulin secretion or induce pancreatic $\beta$-cell dysfunction, resulting in impaired glucose tolerance and type 2 diabetes $^{(4)}$. GI has proven to be a useful nutritional concept, providing insight into the relationship between food and health ${ }^{(6)}$.

GI values of carbohydrate-rich foods vary widely due to physiological and nutritional factors including digestibility, nutrient composition, particle size and methods used for cooking and food processing. Dietary protein, fat and fibre can alter digestibility and gastrointestinal transit time and affect glucose absorption, and some fatty acids and amino acids cause insulin and glucagon secretion and thereby affect blood glucose level $^{(7)}$. Different cooking or processing methods (boiling, roasting, baking and frying) also affect the properties of foods and their GI values ${ }^{(8)}$. As a result, the GI values for a single food type can vary widely for different cooking or processing methods (e.g. different manufacturers).

GI values are evaluated based on glycaemic responses to isoglucidic amounts of foods (same amount of available carbohydrate), which often do not represent a typical serving size $^{(6)}$. The concept of glycaemic load (GL) was introduced to address serving size. GL provides an estimate of the glycaemic effect of a standard portion of food, taking into account both GI and the amount of carbohydrate consumed ${ }^{(6)}$.

Previous studies on GI which are the basis of international GI tables have been conducted mainly in Western countries ${ }^{(3,6,9)}$. There are only a few published databases listing GI and GL values for foods prepared and consumed in Asia ${ }^{(8,10,11)}$, and these do not reflect the diversity of foods, ingredients and cooking methods used throughout Asia. Korean food occupies

Abbreviations: GI, glycaemic index; GL, glycaemic load; ISO, International Standards Organization.

* Corresponding author: Dr H. Lim, fax +82 2969 7717, email hjlim@khu.ac.kr 
a prime position in Asian cuisine and is typified by a highcarbohydrate diet including cereal grains, noodles, bread and starchy vegetables prepared using a variety of methods. There is a need for information on GI values for foods, how these values vary with cooking method and how much of different foods are consumed by Koreans in practice (included in GL values). In this study, we provide a comprehensive list of GI and GL values for common Korean carbohydrate-rich foods according to the food type and cooking methods by healthy individuals.

\section{Methods \\ Subjects}

A total of 195 healthy male volunteers were recruited through open recruitment, and a total of 152 subjects were enrolled in the study. Before inclusion, potential participants were briefed on all aspects of the experiments. Following subjects' consent, health examinations were performed, which included anthropometric measurements and health questionnaires addressing foods allergies or intolerances, metabolic disease, smoking habits and exercise. Participants who met the following inclusion criteria were enrolled: age 19-40 years; stable body weight; BMI $\geq 18.5$ and $<23.0 \mathrm{~kg} / \mathrm{m}^{2}$; systolic blood pressure 110 $120 \mathrm{mmHg}$; diastolic blood pressure $75-85 \mathrm{mmHg}$; fasting blood glucose $<5.5 \mathrm{mmol} / \mathrm{l}$; no known food allergy or intolerance; no medications known to affect glucose tolerance; no history of diabetes mellitus or use of antihyperglycaemic drugs or insulin injection to treat diabetes or related conditions; no major medical or surgical event requiring hospitalisation within the preceding 3 months; no diseases or $\operatorname{drug}(\mathrm{s})$ that influence digestion or nutrient absorption; and no use of steroids, protease inhibitors or antipsychotics (all of which have major effects on glucose metabolism and body fat distribution).

Anthropometric measurements were performed with subjects in a fasting state. BMI and percentage body fat were determined using a body composition analyser (Inbody 720; Biospace Co.).

The study was conducted according to the guidelines of the Declaration of Helsinki, and all procedures involving human subjects were approved by the ethical research board of Kyung Hee University Hospital (no. KMC IRB 1306-01).

All analyses were performed at the Kyung Hee University in Seoul, South Korea. The protocol was adapted from the FAO/ $\mathrm{WHO}^{(1)}$ and International Standards Organization (ISO) 2010 ${ }^{(12)}$ and from other GI evaluation methodology ${ }^{(13)}$

\section{Study protocol}

In accordance with ISO 2010 guidelines ${ }^{(12)}$, tests of forty-nine food items in four categories (cereal grains, noodles and pasta, breads and other processed grains and starchy vegetables) were classified into twelve series of sets. One set consisted of test for reference food (glucose) twice and two to six different foods. For each set, fifteen subjects were recruited, and then tested reference food twice and two to six different foods. All subjects tested the reference food (glucose) twice, and then two to six different foods for total of four to eight tests on separate days in one set. To determine the GI of a food with sufficient power and precision, ISO 2010 recommends performing the test with a minimum of ten subjects ${ }^{(12)}$, thus, fifteen subjects were recruited for each set, twelve to fourteen subjects were enrolled, and a minimum of ten subjects were tested. Subjects were asked to consume no alcohol on the evening before the test, to perform no vigorous exercise the morning of the test and to avoid eating or drinking anything except water for $10 \mathrm{~h}$ before the test.

\section{Test foods}

A total of forty-nine carbohydrate-rich foods representing the diversity of foods commonly consumed in Korea were selected from the Korean National Health and Nutrition Examination Survey food database (Table 1$)^{(14)}$. Foods were categorised as cereal grains ( $n$ 10; including white rice, glutinous white rice and barley), noodles and pasta ( $n$ 9; fine noodles, fresh wheat noodles, wheat dough pieces, udon noodles, spaghetti, rice noodles, ramyeon, buckwheat noodles and sweet potato starch vermicelli), breads and other processed grains ( $n$ 13; white bread, rye bread, rice bread, castella, bread rolls and bagels, pancakes, breakfast cereals and starch jellies) and starchy vegetables ( $n$ 17; maize, potatoes, sweet potatoes, chestnuts, red beans and sweet pumpkin). Foods were selected based on the market share of the producer and were obtained from representative producing areas. Foods were prepared without seasoning using conventional cooking methods such as boiling, steaming, baking, porridge-making, puffing and frying. Foods were cooked on the same day as they were consumed and were offered in a typical portion size and at moderate temperature (tepid) to avoid retrogradation of starch. All foods were tested in equivalent available carbohydrate amounts $(50 \mathrm{~g})$. Glucose was used as the reference food ${ }^{(12)}$. Available carbohydrate values were determined from the Food Composition Table from the Rural Development Administration in Korea $^{(15)}$ or from the manufacturer. Table 1 lists the test foods along with their ingredients and preparation methods. Subjects consumed test or reference foods at an even pace within a period of $15 \mathrm{~min}$ and were provided one cup $(250 \mathrm{ml})$ of water. Subjects were encouraged to minimise physical activity during testing.

\section{Blood glucose measurements}

A qualified technician performed blood glucose measurements in venous blood. A fasting blood sample was taken at $0 \mathrm{~min}$, and the reference or test food was consumed immediately. Further blood samples were collected at 15, 30, 60, 90 and $120 \mathrm{~min}$ and were assayed for glucose level. Blood glucose concentrations were measured using glucose-hexokinase method (Glu Reagent kit; Roche Diagnostics Ltd) by chemistry analyser (Modular PE, Modular Analytics; Roche Diagnostics Ltd).

\section{Calculation of glycaemic index and glycaemic load}

Mean blood glucose concentration of all subjects at each time point were calculated and used to plot average blood glucose 
Table 1. Ingredients and preparation methods of Korean carbohydrate-rich foods

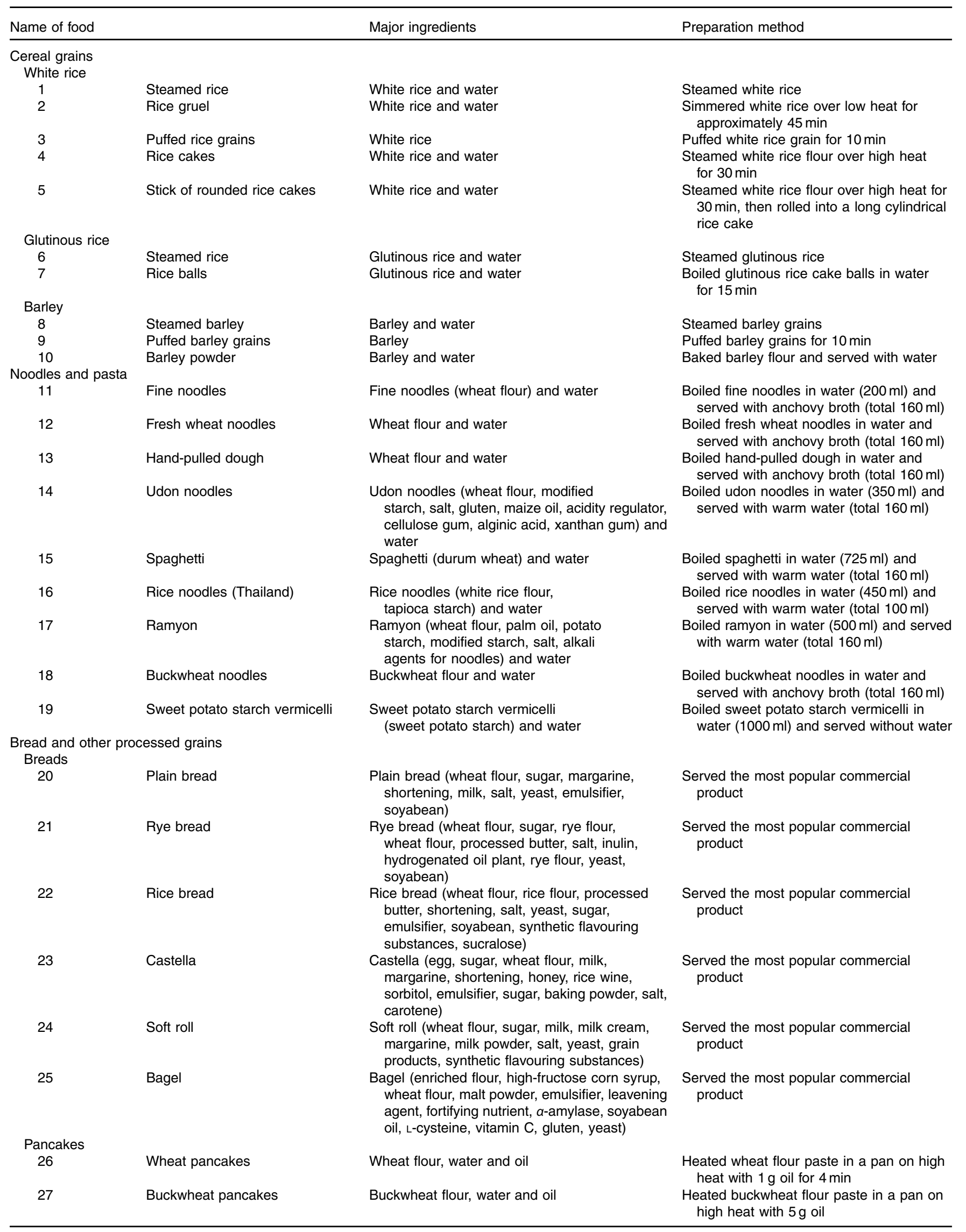


Table 1. Continued

\begin{tabular}{|c|c|c|c|}
\hline Name of food & & Major ingredients & Preparation method \\
\hline \multicolumn{4}{|c|}{ Breakfast cereals } \\
\hline 28 & $\begin{array}{l}\text { Cornflakes, maize bran } \\
\text { (Kellogg's Inc., South Korea) }\end{array}$ & $\begin{array}{l}\text { Maize, sugar, malt-digested taffy, } \\
\text { salt and mixed formulation }\end{array}$ & $\begin{array}{l}\text { Served the most popular commercial } \\
\text { product without water }\end{array}$ \\
\hline 29 & $\begin{array}{l}\text { Cornflakes, All-bran } \\
\quad \text { (Kellogg's Inc., South Korea) }\end{array}$ & $\begin{array}{l}\text { Maize, whole wheat, sugar, salt, } \\
\text { brown rice, oats, barley, high- } \\
\text { fructose corn syrup and } \\
\text { mixed formulation }\end{array}$ & $\begin{array}{l}\text { Served the most popular commercial } \\
\text { product without water }\end{array}$ \\
\hline \multicolumn{4}{|l|}{ Starch jellies } \\
\hline 30 & Acorn jelly & Acorn starch and water & $\begin{array}{l}\text { Stirred acorn starch in water, heated and } \\
\text { then allowed to solidify in the fridge }\end{array}$ \\
\hline 31 & Green bean jelly & Green bean starch and water & $\begin{array}{l}\text { Stirred green bean starch in water, heated } \\
\text { and then allowed to solidify in the fridge }\end{array}$ \\
\hline 32 & Buckwheat jelly & $\begin{array}{l}\text { Buckwheat starch }(75 \%) \text {, green } \\
\text { bean starch ( } 25 \%) \text { and water }\end{array}$ & $\begin{array}{l}\text { Stirred starch in water, heated and then } \\
\text { allowed to solidify in the fridge }\end{array}$ \\
\hline \multicolumn{4}{|c|}{ Starchy vegetables } \\
\hline \multicolumn{4}{|c|}{ Potatoes } \\
\hline 33 & Steamed potatoes & Potatoes and water & Steamed potatoes in high heat for $35 \mathrm{~min}$ \\
\hline 34 & Baked potatoes & Potatoes & Baked potatoes for $30 \mathrm{~min}$ \\
\hline 35 & Deep-fried potatoes (French fries) & Potatoes and oil (1400 ml) & Fried sliced potatoes for $10 \mathrm{~min}$ \\
\hline 36 & Pan-fried potatoes & Potatoes and oil $(50 \mathrm{ml})$ & $\begin{array}{l}\text { Blend the potato in a mixer with water } \\
(30 \mathrm{ml}) \text {, drain the water from the potato } \\
\text { puree and then fried solid ingredients with } \\
50 \mathrm{ml} \text { oil for } 15 \mathrm{~min}\end{array}$ \\
\hline 37 & Potato starch steamed & Potato starch and water & Steamed potato starch paste for $25 \mathrm{~min}$ \\
\hline \multicolumn{4}{|c|}{ Sweet potatoes } \\
\hline 38 & Steamed sweet potatoes & Sweet potatoes and water & Steamed sweet potatoes for $35 \mathrm{~min}$ \\
\hline 39 & Baked sweet potatoes & Sweet potatoes & Baked sweet potatoes for $30 \mathrm{~min}$ \\
\hline 40 & Deep-fried sweet potatoes & Sweet potatoes and oil & Fried sliced sweet potatoes for $5 \mathrm{~min}$ \\
\hline \multicolumn{4}{|l|}{ Chestnuts } \\
\hline 41 & Steamed chestnuts & Chestnuts and water & Steamed chestnuts for $25 \mathrm{~min}$ \\
\hline 42 & Baked chestnuts & Chestnuts & Baked chestnuts for $30 \mathrm{~min}$ \\
\hline \multicolumn{4}{|l|}{ Maize } \\
\hline 43 & Steamed maize & Maize and water & Steamed maize for $40 \mathrm{~min}$ \\
\hline 44 & Maize gruel & Maize and water & Ground maize and simmered for $20 \mathrm{~min}$ \\
\hline 45 & Puffed maize grains (popcorn) & Maize & Puffed maize grains for $10 \mathrm{~min}$ \\
\hline \multicolumn{4}{|l|}{ Red beans } \\
\hline 46 & Boiled red beans & Red beans and water & Boiled red beans for $80 \mathrm{~min}$ \\
\hline 47 & Red bean gruel & Red beans and water & Boiled red beans for $100 \mathrm{~min}$ and mashed \\
\hline \multicolumn{4}{|r|}{ 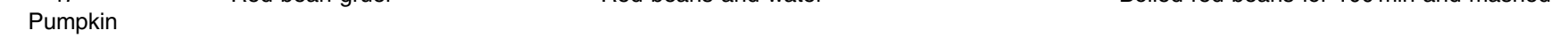 } \\
\hline 48 & Steamed sweet pumpkin & Pumpkin and water & Steamed pumpkin for $15 \mathrm{~min}$ \\
\hline 49 & Sweet pumpkin gruel & Pumpkin and water & Boiled pumpkin for $20 \mathrm{~min}$ and mashed \\
\hline
\end{tabular}

response curves. The incremental area under the blood glucose curve (IAUC) was calculated using the trapezoid rule, and the area below the fasting baseline was ignored. Calculations were performed using GraphPad Prism (version 6, GraphPad Software).

GI for each test food eaten by each subject was calculated using the equation: GI= (IAUC test food/IAUC reference food) $\times 100$. The GI of each food was calculated as the mean GI for all subjects consuming that food. Foods were classified into low $(\leq 55)$, medium $(56-69)$ or high $(\geq 70) \mathrm{GI}^{(9)}$.

GL was calculated using the equation: $\mathrm{GL}=(\mathrm{GI} \times$ available carbohydrate in a typical serving size $(\mathrm{g})) / 100^{(9)}$. The serving size of each food was obtained from standard food portion size references ${ }^{(16-18)}$ or from the manufacturer's information.

\section{Statistical analyses}

All statistical analyses were performed using SPSS (version 22.0; IBM Corporation). GI values are reported as means with their standard errors, as in the ISO methodology ${ }^{(12)}$. One-way
ANOVA and Duncan's multiple range test were used to compare the GI values within food categories. Statistical significance was set at $P<0 \cdot 05$.

\section{Results}

The mean age of the 149 male participants was 23.3 (sEm 1.9) years (range, 20-34 years). Mean BMI was 21.6 (SEM 1.1$) \mathrm{kg} / \mathrm{m}^{2}$ (range, $19 \cdot 0-23.4 \mathrm{~kg} / \mathrm{m}^{2}$ ) and mean body fat was 16.6 (sem $3 \cdot 6$ ) $\%$ (range, $7 \cdot 6-24 \cdot 7 \%$ ). The average fasting blood glucose concentration was $5 \cdot 1$ (sem 0.4) $\mathrm{mmol} / \mathrm{l}$ (range, $4 \cdot 6-5.4 \mathrm{mmol} / \mathrm{l}$ ). Anthropometric characteristics are reported in Table 2. Based on ISO 2010, $0.8 \%$ of individual GI measurements were excluded because they exceeded the mean by at least two standard deviations.

Table 3 lists the GI and GL values for all forty-nine tested foods. GI values for cereal grains ranged from low (35.4 for cooked barley) to high ( 96.9 for rice balls), and GL values for cereal grains ranged from medium (10.4 for barley powder) to 
Table 2. Baseline characteristics of study subjects ( $n$ 152) (Mean values and standard deviations)

\begin{tabular}{lcc}
\hline Variables & Mean & SD \\
\hline Age (years) & 23.3 & 1.9 \\
BMl $\left(\mathrm{kg} / \mathrm{m}^{2}\right)$ & 21.6 & $1 \cdot 1$ \\
Body fat $(\%)$ & 16.6 & 3.6 \\
Fasting blood glucose $(\mathrm{mmol} /)^{*}$ & 5.1 & 0.4 \\
\hline
\end{tabular}

* Fasting blood glucose under $5.5 \mathrm{mmol} / \mathrm{l}$ measured in capillary whole blood obtained by a finger prick (Accu-check; Roche)

high ( 71.6 for steamed glutinous rice). The GI of rice gruel was significantly higher than that of rice cakes $(P<0 \cdot 05)$. There was no difference in GI for different cooking methods of glutinous rice. In food made with barley, powdered barley had a significantly higher GI than steamed barley $(P<0 \cdot 05)$.

For noodles and pasta, GI showed a narrow low to medium range, from 48.2 for fresh wheat noodles to 60.0 for sweet potato starch vermicelli; noodles and pasta had GL values that ranged from medium to high (10.6 for sweet potato starch vermicelli to $44 \cdot 6$ for ramyeon).

For bread, the GI ranged from medium to high $(56 \cdot 2$ for soft rolls to 77.4 for bagels) and GL ranged from medium to high (12.2 for soft rolls to 26.0 for bagels). GI of other processed grains ranged from low to high (49.9 for pan-fried buckwheat to 71.7 for acorn jelly) and GL values ranged from low to medium (1.9 for green bean jelly to 16.6 for wheat pancakes).

Starchy vegetables showed a range of GI values, from low for chestnuts, pumpkin and red beans, to medium to high for maize. The GI of potatoes and sweet potatoes differed according to the cooking method $(P<0.05)$. The GL values ranged from low to high ( 1.8 for boiled red beans to 33.0 for maize gruel).

Fig. 1 shows the GI and GL values of grains and starchy vegetables by different cooking methods. GI values of foods varied widely by different cooking methods. For example, for steamed grains, glutinous rice had a high GI, white rice medium GI and barley low GI, and for gruel, rice and maize had high GI, and red beans and pumpkin low GI. For steamed vegetables, only sweet pumpkin had a low GI, and for baked vegetables, chestnuts had low GI, and for frying, potato had low GI.

The GI and GL values of carbohydrate-rich foods are combined in a two-dimensional grid in Fig. 2. Cereal grains had GI values that vary widely from low to high and GL mainly from medium to high. Noodles and pasta had GI values ranging from low to medium (40-60; at the centre of the grid) but high GL values except for sweet potato starch vermicelli. Bread and other processed grains had medium GI and GL values. Starchy vegetables had a wide range of GI depending on the food type and cooking method but low GL values.

\section{Discussion}

We found that the GI and GL values of forty-nine carbohydraterich foods varied between food type and between cooking methods for the same food type.
This data set provides a useful reference for guiding food choices and demonstrates that GI values are influenced not only by species ${ }^{(19)}$ but also by structural characteristics such as particle size and shape ${ }^{(19)}$, starch content (e.g. amylose $v$. amylopectin $)^{(20)}$, soluble fibre amount ${ }^{(21)}$ and cooking $\operatorname{method}^{(19,20)}$. Cereal grains, which are a major source of energy in the Korean diet, tend to have high GL values and the widest range of GI values according to cooking method. Noodles are often used as the main meal ingredient instead of rice in Korea and were also found to have high GL despite a low to medium GI due to the large amount of carbohydrates in a typical serving. Bread and other carbohydrate products have intermediate GI and GL values because of their structural properties and portion size ${ }^{(20)}$. The GI values for food made with starchy vegetables varied widely for different cooking but tended to have low GL values due to smaller amounts of carbohydrates in a typical portion.

Several characteristics of carbohydrate-rich foods can alter their GI values. First, they might be composed of different species of starches and have different fibre contents. For example, glutinous rice has a higher GI than white rice because of the relative percentages of amylopectin and amylose ${ }^{(20)}$. Amylopectin has a high absorption rate and causes high blood glucose because digestive enzymes can easily access the structure of the starch chain; the opposite is true for amylosecontaining starch ${ }^{(20)}$. Barley, unlike rice, has a low GI, possibly due to the soluble dietary fibre $\beta$-glucan ${ }^{(21,22)}$. Second, different processing methods can influence the GI of a particular food ${ }^{(8)}$. For example, compressed and steamed white rice cakes are both made from rice flour, but compressed cakes have a stronger and stickier structure from extrusion during manufacturing, resulting in less mastication, slower digestion and lower postprandial glucose response ${ }^{(23)}$. The results revealed marked variation in GI with different cooking methods for a single food type. For example, steamed rice, rice gruel, puffed rice, boiled rice cakes and boiled and pressed rice cakes showed a wide range of GI values because these cooking methods have different effects on gelatinisation and digestibility ${ }^{(23)}$. Avoiding rapid changes in blood glucose is important for healthy adults and diabetics. Eating low-GI foods results in a lower maximum postprandial glucose levels and a slower decrease in blood glucose than intake of high-GI foods ${ }^{(2)}$. HighGI rice foods in our study included porridge, puffed rice grains and steamed rice cakes (but not regular steamed rice); high-GI starchy vegetables included steamed and baked potatoes and sweet potatoes, steamed maize and maize gruel.

It has been reported that structural properties affect the glycaemic responses to carbohydrate-rich processed foods ${ }^{(20)}$. Fine noodles and fresh wheat noodles might have similar GI values because of their similar structural properties. Differences in GI values among noodles and spaghetti products and among breads might be due to the differences in ingredients, starch structure and processing conditions ${ }^{(20)}$. Buckwheat pancakes had a low GI, while wheat pancakes had a medium GI, possibly because buckwheat contains the iminosugar D-fagomine, which slows the postprandial release of glucose from carbohydrates by inhibiting intestinal disaccharidases ${ }^{(24)}$. Cornflakes were expected to have a higher GI than All-bran, but in our study these two 


\section{NS British Journal of Nutrition}

Table 3. Glycaemic index (GI) and glycaemic load (GL) values for Korean carbohydrate-rich foods (Mean values with their standard errors)

\begin{tabular}{|c|c|c|c|c|c|c|c|c|c|c|c|}
\hline \multirow[b]{2}{*}{ Food } & & \multirow{2}{*}{$\begin{array}{l}\text { Carbohydrate } \\
(\mathrm{g} / 100 \mathrm{~g})\end{array}$} & \multirow{2}{*}{$\begin{array}{l}\text { Experimental } \\
\text { portion }(g)\end{array}$} & \multicolumn{2}{|c|}{ Gl } & \multirow{2}{*}{$\begin{array}{c}\text { Gl } \\
\text { classification }\end{array}$} & \multirow{2}{*}{$\begin{array}{l}\text { Standard } \\
\text { serving } \\
\text { size }(\mathrm{g})\end{array}$} & \multirow{2}{*}{$\begin{array}{l}\text { Carbohydrate } \\
\text { (g/serving) }\end{array}$} & \multirow{2}{*}{$\begin{array}{c}\mathrm{GL} \\
\text { (per serving) }\end{array}$} & \multirow{2}{*}{$\begin{array}{c}\mathrm{GL} \\
\text { classification }\end{array}$} & \multirow{2}{*}{$\begin{array}{l}\text { Subjects } \\
\qquad(n)\end{array}$} \\
\hline & & & & Mean & SEM & & & & & & \\
\hline \multicolumn{12}{|c|}{ Cereal grains } \\
\hline \multicolumn{12}{|c|}{ White rice ${ }^{*}$} \\
\hline 1 & Steamed rice & 34.9 & $143 \cdot 3$ & $69 \cdot 9^{a, b}$ & 5.7 & Med & $210 \cdot 0$ & $73 \cdot 3$ & $51 \cdot 2$ & High & 8 \\
\hline 2 & Rice gruel & $11 \cdot 2$ & $447 \cdot 7$ & $92 \cdot 5^{\mathrm{a}}$ & 8.8 & High & $250 \cdot 0$ & $27 \cdot 9$ & $25 \cdot 8$ & High & 10 \\
\hline 3 & Puffed rice grains & $89 \cdot 0$ & $56 \cdot 2$ & $72 \cdot 4^{\mathrm{a}, \mathrm{b}}$ & $6 \cdot 6$ & High & $25 \cdot 0$ & $22 \cdot 2$ & $16 \cdot 1$ & Med & 10 \\
\hline 4 & Rice cakes & $53 \cdot 3$ & $93 \cdot 8$ & $80 \cdot 7^{\mathrm{a}, \mathrm{b}}$ & 8.5 & High & $95 \cdot 0$ & $50 \cdot 6$ & $40 \cdot 9$ & High & 10 \\
\hline 5 & Stick of rounded rice cakes & 61.5 & $81 \cdot 3$ & $50 \cdot 6^{\mathrm{b}}$ & $7 \cdot 2$ & Low & $130 \cdot 0$ & $80 \cdot 0$ & 40.5 & High & 9 \\
\hline \multicolumn{12}{|c|}{ Glutinous rice } \\
\hline 6 & Steamed rice & $45 \cdot 0$ & $111 \cdot 1$ & $75 \cdot 7$ & $10 \cdot 6$ & High & $210 \cdot 0$ & 94.5 & 71.6 & High & 10 \\
\hline 7 & Rice balls & $50 \cdot 0$ & $100 \cdot 0$ & $96 \cdot 9$ & $15 \cdot 1$ & High & $60 \cdot 0$ & $30 \cdot 0$ & $29 \cdot 1$ & High & 10 \\
\hline \multicolumn{12}{|c|}{ Barley* } \\
\hline 8 & Steamed barley & $28 \cdot 9$ & $173 \cdot 1$ & $35 \cdot 4^{b}$ & $9 \cdot 2$ & Low & $210 \cdot 0$ & $60 \cdot 7$ & 21.5 & High & 9 \\
\hline 9 & Puffed barley grains & $87 \cdot 1$ & 57.4 & $63 \cdot 3^{a, b}$ & $8 \cdot 2$ & Med & $25 \cdot 0$ & 21.8 & $13 \cdot 8$ & Med & 9 \\
\hline 10 & Barley powder & 74.6 & $67 \cdot 0$ & $69 \cdot 8^{\mathrm{a}}$ & $6 \cdot 7$ & Med & $20 \cdot 0$ & 14.9 & $10 \cdot 4$ & Med & 11 \\
\hline \multicolumn{12}{|c|}{ Noodles and pasta } \\
\hline 11 & Fine noodles & $76 \cdot 0$ & $65 \cdot 8$ & 49.0 & $7 \cdot 0$ & Low & $90 \cdot 0$ & $68 \cdot 4$ & 33.5 & High & 13 \\
\hline 12 & Fresh wheat noodles & 54.6 & 91.5 & $48 \cdot 2$ & 4.9 & Low & $150 \cdot 0$ & $82 \cdot 0$ & 39.5 & High & 13 \\
\hline 13 & Hand-pulled dough & 54.7 & $91 \cdot 4$ & $50 \cdot 2$ & 5.6 & Low & $150 \cdot 0$ & $82 \cdot 1$ & $41 \cdot 2$ & High & 14 \\
\hline 14 & Udon noodles & $32 \cdot 8$ & $152 \cdot 4$ & $56 \cdot 5$ & $8 \cdot 1$ & Med & $210 \cdot 0$ & $68 \cdot 9$ & 38.9 & High & 8 \\
\hline 15 & Spaghetti & $69 \cdot 0$ & 72.5 & $55 \cdot 3$ & 6.5 & Med & $85 \cdot 0$ & 58.6 & $32 \cdot 4$ & High & 11 \\
\hline 16 & Rice noodles (Thailand) & $32 \cdot 1$ & $156 \cdot 0$ & $52 \cdot 2$ & $10 \cdot 7$ & Low & $180 \cdot 0$ & 57.7 & $30 \cdot 1$ & High & 9 \\
\hline 17 & Ramyon & $69 \cdot 2$ & $72 \cdot 3$ & $49 \cdot 3$ & $10 \cdot 2$ & Low & $130 \cdot 8$ & $90 \cdot 5$ & $44 \cdot 6$ & High & 9 \\
\hline 18 & Buckwheat noodles & 71.2 & $70 \cdot 2$ & 59.6 & $13 \cdot 3$ & Med & $90 \cdot 0$ & $64 \cdot 1$ & $38 \cdot 2$ & High & 13 \\
\hline 19 & Sweet potato starch vermicelli & $88 \cdot 0$ & $56 \cdot 8$ & $60 \cdot 0$ & 11.6 & Med & 20 & $17 \cdot 6$ & $10 \cdot 6$ & Med & 11 \\
\hline \multicolumn{12}{|c|}{ Bread and other processed grains } \\
\hline \multicolumn{12}{|c|}{ Breads } \\
\hline 20 & Plain bread & $42 \cdot 9$ & $116 \cdot 6$ & $70 \cdot 7$ & 11.4 & High & 55 & $23 \cdot 6$ & $16 \cdot 7$ & Med & 10 \\
\hline 21 & Rye bread & $45 \cdot 7$ & $109 \cdot 4$ & 64.9 & $18 \cdot 4$ & Med & 55 & $25 \cdot 1$ & $16 \cdot 3$ & Med & 10 \\
\hline 22 & Rice bread & $42 \cdot 9$ & $116 \cdot 6$ & $73 \cdot 4$ & $7 \cdot 6$ & High & 55 & $23 \cdot 6$ & $17 \cdot 3$ & Med & 11 \\
\hline 23 & Castella & 43.8 & $114 \cdot 2$ & 59.9 & $13 \cdot 3$ & Med & $50 \cdot 0$ & 21.9 & $13 \cdot 1$ & Med & 10 \\
\hline 24 & Soft roll & $48 \cdot 3$ & 103.5 & $56 \cdot 2$ & $11 \cdot 1$ & Med & $45 \cdot 0$ & $21 \cdot 7$ & $12 \cdot 2$ & Med & 10 \\
\hline 25 & Bagel & 48.0 & $104 \cdot 1$ & 77.4 & 11.5 & High & $70 \cdot 0$ & $33 \cdot 6$ & $26 \cdot 0$ & High & 11 \\
\hline \multicolumn{12}{|c|}{ Pancakes } \\
\hline 26 & Wheat pancakes & 48.6 & $102 \cdot 8$ & $57 \cdot 0$ & $9 \cdot 7$ & Med & $60 \cdot 0$ & $29 \cdot 2$ & $16 \cdot 6$ & Med & 14 \\
\hline 27 & Buckwheat pancakes & 29.5 & $169 \cdot 4$ & 49.9 & 8.9 & Low & $60 \cdot 0$ & $17 \cdot 7$ & 8.8 & Low & 13 \\
\hline \multicolumn{12}{|c|}{ Breakfast cereals } \\
\hline 28 & $\begin{array}{l}\text { Cornflakes (Kellogg's Inc., South } \\
\text { Korea) }\end{array}$ & $89 \cdot 0$ & $56 \cdot 2$ & $51 \cdot 6$ & $10 \cdot 7$ & Low & 30 & $26 \cdot 7$ & $13 \cdot 8$ & Med & 14 \\
\hline 29 & All-bran (Kellogg's Inc., South Korea) & $87 \cdot 0$ & $57 \cdot 5$ & $51 \cdot 4$ & $11 \cdot 1$ & Low & 30 & $26 \cdot 1$ & $13 \cdot 4$ & Med & 11 \\
\hline Starch & & & & & & & & & & & \\
\hline 30 & Acorn jelly & $13 \cdot 8$ & $361 \cdot 2$ & 71.7 & $16 \cdot 0$ & High & $70 \cdot 0$ & 9.7 & 6.9 & Low & 12 \\
\hline 31 & Green bean jelly & $11 \cdot 3$ & $443 \cdot 2$ & $55 \cdot 1$ & 8.9 & Med & 30 & 3.4 & 1.9 & Low & 14 \\
\hline 32 & Buckwheat jelly & $15 \cdot 7$ & 318.5 & $65 \cdot 7$ & $11 \cdot 8$ & Med & $70 \cdot 0$ & $11 \cdot 0$ & $7 \cdot 2$ & Low & 13 \\
\hline Starchy & & & & & & & & & & & \\
\hline Potatc & & & & & & & & & & & \\
\hline 33 & Steamed potatoes $\dagger$ & $13 \cdot 9$ & $359 \cdot 7$ & $93 \cdot 6^{\mathrm{a}}$ & $11 \cdot 6$ & High & 65 & 9.0 & 8.5 & Low & 9 \\
\hline 34 & Baked potatoes $†$ & 13.9 & 359.7 & $78 \cdot 2^{\mathrm{a}, \mathrm{b}}$ & 14.5 & High & 65 & 9.0 & $7 \cdot 1$ & Low & 9 \\
\hline 35 & Deep-fried potatoes (French fries) $\dagger$ & 21.0 & 238.5 & $41 \cdot 5^{\mathrm{a}, \mathrm{b}}$ & 7.8 & Low & $115 \cdot 0$ & 24.1 & $10 \cdot 0$ & Low & 8 \\
\hline
\end{tabular}




\section{NS British Journal of Nutrition}

Table 3. Continued

\begin{tabular}{|c|c|c|c|c|c|c|c|c|c|c|c|}
\hline \multirow[b]{2}{*}{ Food } & & \multirow{2}{*}{$\begin{array}{c}\text { Carbohydrate } \\
(\mathrm{g} / 100 \mathrm{~g})\end{array}$} & \multirow{2}{*}{$\begin{array}{l}\text { Experimental } \\
\text { portion }(\mathrm{g})\end{array}$} & \multicolumn{2}{|c|}{ Gl } & \multirow{2}{*}{$\begin{array}{c}\mathrm{Gl} \\
\text { classification }\end{array}$} & \multirow{2}{*}{$\begin{array}{l}\text { Standard } \\
\text { serving } \\
\text { size }(\mathrm{g})\end{array}$} & \multirow{2}{*}{$\begin{array}{c}\text { Carbohydrate } \\
\text { (g/serving) }\end{array}$} & \multirow{2}{*}{$\begin{array}{c}\mathrm{GL} \\
\text { (per serving) }\end{array}$} & \multirow{2}{*}{$\begin{array}{c}\mathrm{GL} \\
\text { classification }\end{array}$} & \multirow{2}{*}{$\begin{array}{l}\text { Subjects } \\
(n)\end{array}$} \\
\hline & & & & Mean & SEM & & & & & & \\
\hline 36 & Pan-fried potatoes $\dagger$ & 23.3 & $215 \cdot 0$ & $28 \cdot 0^{\mathrm{b}}$ & $5 \cdot 1$ & Low & $150 \cdot 0$ & 34.9 & 9.8 & Low & 7 \\
\hline 37 & Potato starch steamed & $45 \cdot 7$ & $109 \cdot 3$ & $53 \cdot 3^{a, b}$ & $17 \cdot 3$ & Low & 90.0 & $41 \cdot 2$ & 21.9 & High & 12 \\
\hline \multicolumn{12}{|c|}{$\begin{array}{l}\text { Sweet } \\
\text { potatoes }\end{array}$} \\
\hline 38 & Steamed sweet potatoes $\dagger$ & $31 \cdot 2$ & $160 \cdot 3$ & $70 \cdot 8^{\mathrm{a}, \mathrm{b}}$ & $6 \cdot 1$ & High & $70 \cdot 0$ & 21.8 & $15 \cdot 5$ & Med & 9 \\
\hline 39 & Baked sweet potatoes $\dagger$ & $31 \cdot 2$ & $160 \cdot 3$ & $90 \cdot 9^{\mathrm{a}}$ & 9.6 & High & $70 \cdot 0$ & 21.8 & $19 \cdot 8$ & Med & 10 \\
\hline 40 & Deep-fried sweet potatoes & 46.6 & 107.4 & $57.7^{\mathrm{b}}$ & 10.9 & Med & $45 \cdot 0$ & 21.0 & $12 \cdot 1$ & Med & 9 \\
\hline \multicolumn{12}{|c|}{ Chestnuts } \\
\hline 41 & Steamed chestnuts $\dagger$ & $37 \cdot 1$ & $134 \cdot 8$ & 57.8 & $6 \cdot 3$ & Med & 10 & 3.7 & $2 \cdot 1$ & Low & 13 \\
\hline 42 & Baked chestnuts $†$ & $37 \cdot 1$ & 134.8 & $54 \cdot 3$ & 5.8 & Low & 10 & 3.7 & $2 \cdot 0$ & Low & 11 \\
\hline \multicolumn{12}{|c|}{ Maize } \\
\hline 43 & Steamed maize $†$ & 29.4 & $170 \cdot 1$ & 73.4 & 9.9 & High & $90 \cdot 0$ & 26.5 & $19 \cdot 4$ & Med & 11 \\
\hline 44 & Maize gruel† & 14.4 & 347.4 & 91.8 & 19.5 & High & $250 \cdot 0$ & 36.0 & 33.0 & High & 9 \\
\hline 45 & Puffed maize grains (popcorn) $\dagger$ & $86 \cdot 1$ & $58 \cdot 1$ & 69.9 & 11.4 & Med & $25 \cdot 0$ & 21.5 & $15 \cdot 0$ & Med & 9 \\
\hline \multicolumn{12}{|c|}{ Red beans } \\
\hline 46 & Boiled red beans $†$ & 68.4 & 73.1 & 26.5 & $5 \cdot 2$ & Low & $10 \cdot 0$ & $6 \cdot 8$ & 1.8 & Low & 9 \\
\hline 47 & Red bean gruel† & $20 \cdot 2$ & $247 \cdot 9$ & 38.5 & $7 \cdot 3$ & Low & $250 \cdot 0$ & $50 \cdot 4$ & $19 \cdot 4$ & Med & 10 \\
\hline \multicolumn{12}{|c|}{ Pumpkin } \\
\hline 48 & Steamed sweet pumpkin & $18 \cdot 0$ & $277 \cdot 8$ & $52 \cdot 1$ & $14 \cdot 0$ & Low & $70 \cdot 0$ & $12 \cdot 6$ & 6.6 & Low & 11 \\
\hline 49 & Sweet pumpkin gruel & $10 \cdot 4$ & $478 \cdot 6$ & 53.0 & $16 \cdot 8$ & Low & $250 \cdot 0$ & $26 \cdot 1$ & $13 \cdot 9$ & Med & 9 \\
\hline
\end{tabular}

a,b Mean values in a column with unlike letters were significantly different between groups $(P<0.05)$.

* Significantly different among same food category by ANOVA and Duncan's multiple range test $(P<0.05)$.

† Reproduced by permission of the Korean Society of Food Science and Nutrition ${ }^{(30)}$. 

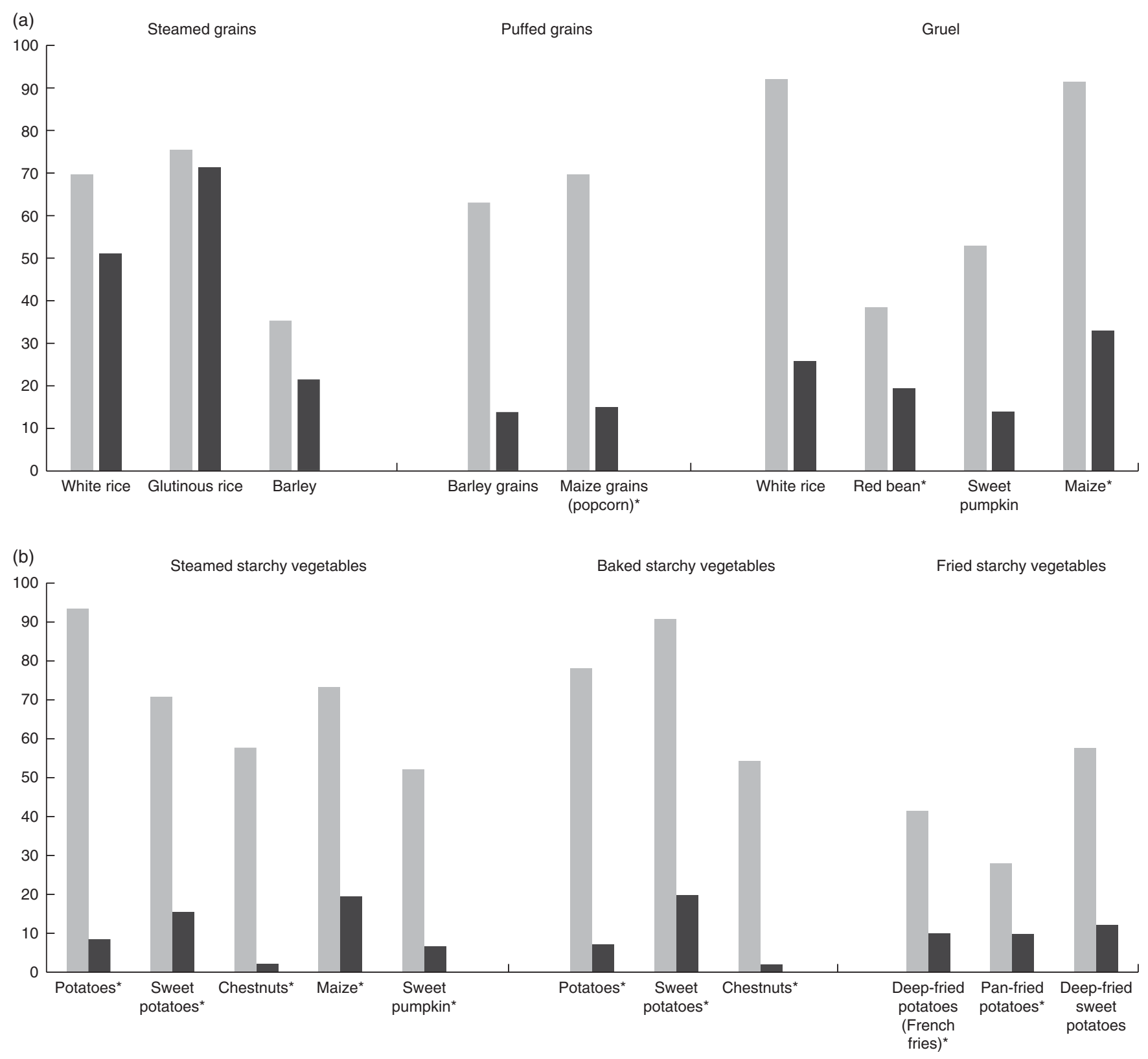

Fig. 1. Glycaemic index $(\square)$ and glycaemic load $(\square)$ of grains and starchy vegetables by different cooking methods. (a) Steamed grains, puffed grains and gruel; (b) steamed, baked and fried starchy vegetables. *Reproduced by permission of the Korean Society of Food Science and Nutrition ${ }^{(30)}$.

breakfast cereals had similar GI values. Acorn, green bean and buckwheat jellies, resulting from the gelation of starch and protein from grains and nuts ${ }^{(25)}$, had medium to high GI. Proteins can affect GI, and the protein content of green beans (24.8\%) is higher than that of acorns $(5 \cdot 8-7 \cdot 8 \%)$ and buckwheat $(10-15 \%)^{(26)}$.

Interestingly, the GI of foods made from maize, potatoes and sweet potatoes tended to be higher than those of other starchy vegetables (e.g. chestnuts, red beans and sweet pumpkin) cooked using similar methods. In this case, food structure, starch content or soluble fibre amount might have influenced the GI values ${ }^{(19,20)}$. Potatoes and sweet potatoes which were pan-fried or deep-fried using oil had lower GI values than similar foods not containing oil. Eating fat reduces the glycaemic response by increasing insulin secretion and slowing gastric emptying by inhibiting amylase ${ }^{(27)}$. However, despite lower GI values, fried food intake should be moderated to prevent chronic metabolic diseases $^{(28)}$. With increasing consumption of meal replacements worldwide, the current GI table will enable consumers and researchers to select low-GI foods for their respective needs. The majority of foods used in meal replacements, such as steamed potatoes and sweet potatoes, produced high GI values; therefore, reducing the consumption of high-GI foods is advisable. Interestingly, low GI values were obtained for foods made of boiled red beans, red bean gruel, steamed sweet pumpkin and sweet pumpkin gruel. These foods may have low GI because of their soluble fibre and antinutrient contents ${ }^{(29)}$. 
(a)

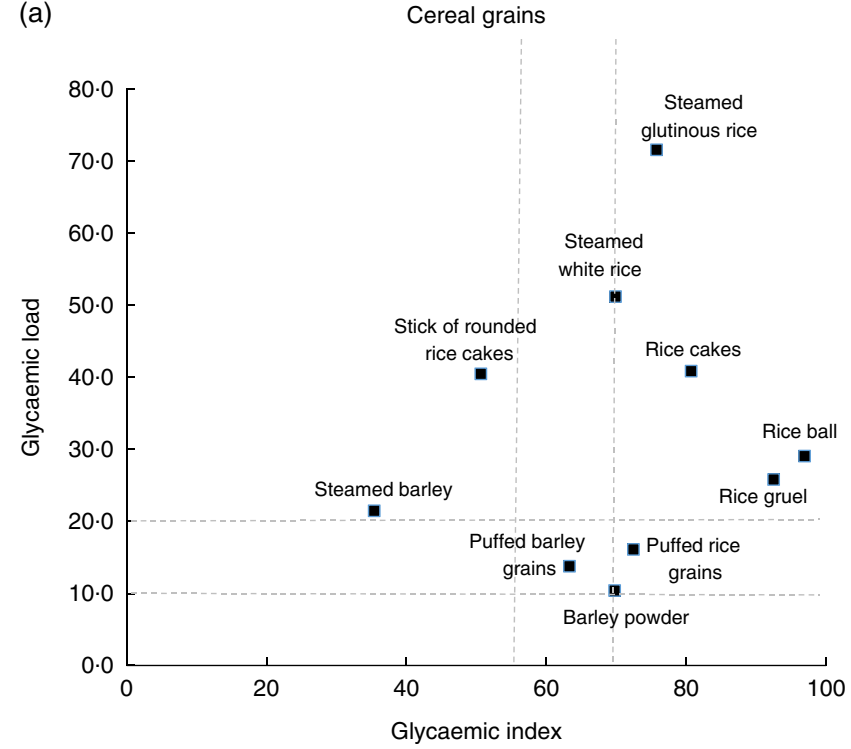

(c)

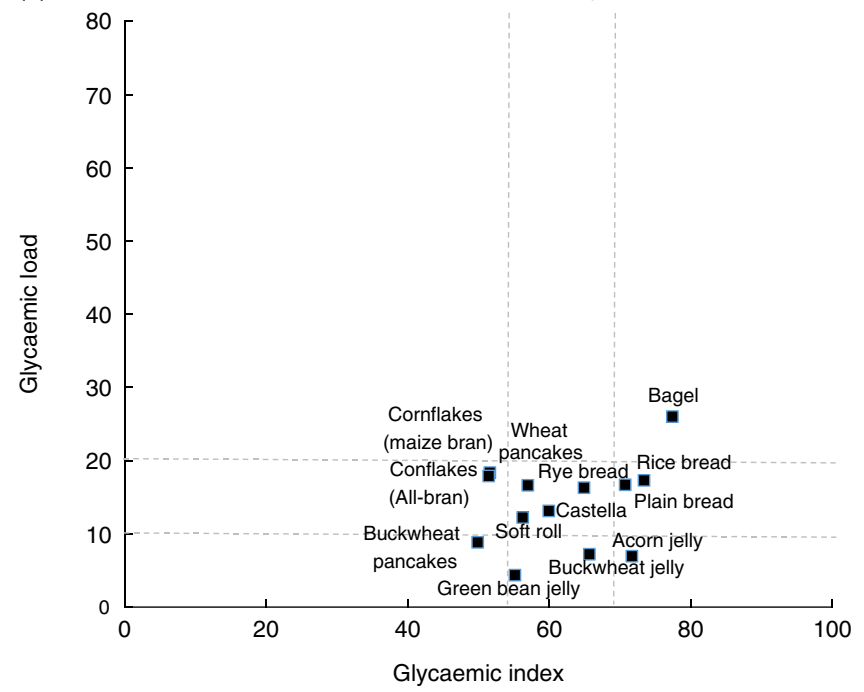

(b)

Noodles and pasta

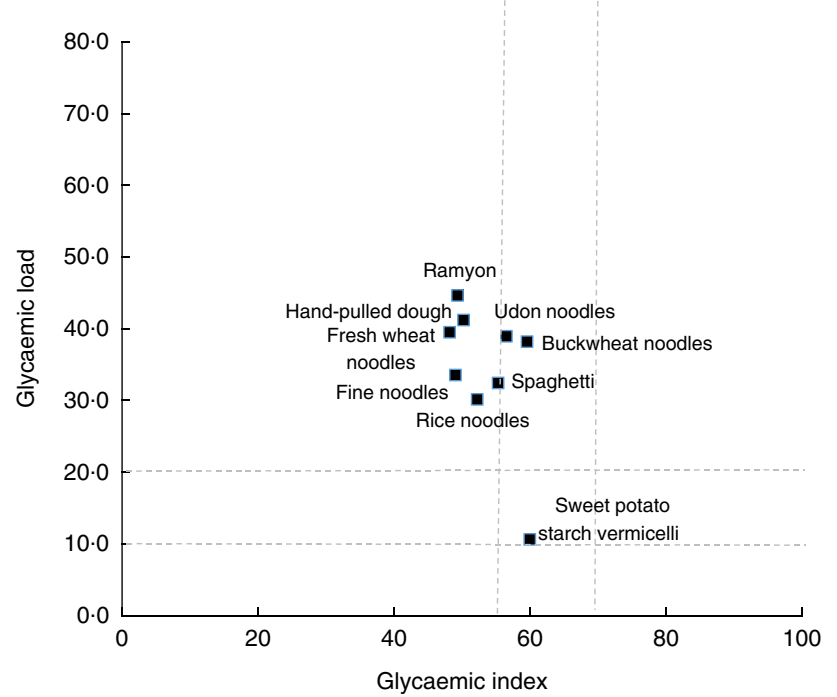

(d)

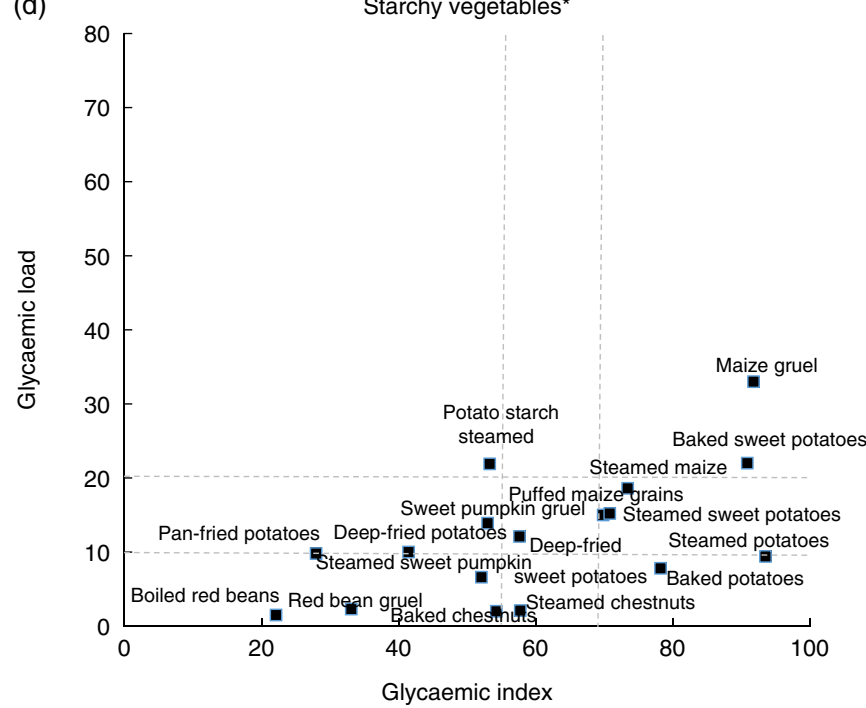

Fig. 2. The relation of glycaemic index and glycaemic load of carbohydrate-rich foods by food categories. (a) Cereal grains, (b) noodles and pasta, (c) bread and other processed grains and (d) starchy vegetables. *Reproduced by permission of the Korean Society of Food Science and Nutrition ${ }^{(30)}$.

As with the GI, high GL indicates the likelihood of a greater elevation in blood glucose. GL accounts for portion size and allows a more representative comparison of glycaemic responses after consumption of portions of food ${ }^{(6)}$. Foods with low GI but high GL included bar rice cakes, cooked barley, fine noodles and steamed potato starch. Even if a food has a low GI, consumers should be concerned about the food's GL value, which predicts the glycaemic response.

Our study had several limitations. GI values of foods should be considered in the context of a mixed meal. One strength of our study is that we provide information for the GI and GL values for Asian foods which are only a few published databases available listing GI and GL values, although Asian foods are gaining in popularity in the world and carbohydrate-rich foods in this region are core foods. We used the protocols of the FAO/WHO (1997) and ISO (2010) to determine GI and GL values. Moreover, we provide GI and GL values for commonly consumed carbohydrate-rich foods processed using standard cooking methods. In conclusion, the present study provides reliable GI and GL values for carbohydrate-rich foods commonly consumed according to food type and cooking methods. The results indicate that cooking or processing methods affect the GI of a particular food. Further studies are needed to investigate how GI values of foods change when consumed in a mixed meal, to improve the information available to the general public and to health professionals on GI and GL. Such additional data will help consumers make better food choices for glycaemic control.

\section{Acknowledgements}

The authors thank Dr Hansongyi Lee for her continued support. The authors also thank Dr Ryowon Choue for her invaluable advice about the research. 
This study was carried out with the support of the Cooperative Research Program for Agricultural Science and Technology Development (project no. PJ009445), Rural Development Administration, Republic of Korea.

The authors' contributions were as follows: H. L. designed the research; D.-Y. K., Y. K. enrolled participants and conducted research; Y. K. analysed the data; D.-Y. K. wrote the first draft of the manuscript; H. L. had primary responsibility for final content and all authors read and approved its final contents.

No conflict of interest is declared by any of the authors.

\section{References}

1. Food and Agriculture Organization \& World Health Organization (1998) Carbohydrates in Human Nutrition. Report of a Joint FAO/WHO Expert Consultation. FAO Food and Nutrition Paper no. 66. Rome: FAO.

2. Jenkins D, Wolever T, Taylor RH, et al. (1981) Glycemic index of foods: a physiological basis for carbohydrate exchange. Am J Clin Nutr 34, 362-366.

3. Scazzina F, Dall'Asta M, Casiraghi MC, et al. (2016) Glycemic index and glycemic load of commercial Italian foods. Nutr Metab Cardiovasc Dis 26, 419-429.

4. Brand-Miller J, Hayne S, Petocz P, et al. (2003) Low-glycemic index diets in the management of diabetes: a meta-analysis of randomized controlled trials. Diabetes Care 26, 2261-2267.

5. Frost G, Leeds A, Trew G, et al. (1998) Insulin sensitivity in women at risk of coronary heart disease and the effect of a low glycemic diet. Metabolism 47, 1245-1251.

6. Foster-Powell K, Holt SH \& Brand-Miller JC (2002) International table of glycemic index and glycemic load values. $A m J$ Clin Nutr 76, 5-56.

7. Meng H, Matthan NR, Ausman LM, et al. (2017) Effect of prior meal macronutrient composition on postprandial glycemic responses and glycemic index and glycemic load value determinations. Am J Clin Nutr 106, 1246-1256.

8. Bahado-Singh P, Wheatley A, Ahmad M, et al. (2006) Food processing methods influence the glycaemic indices of some commonly eaten West Indian carbohydrate-rich foods. $\mathrm{Br} \mathrm{J}$ Nutr 96, 476-481.

9. Atkinson FS, Foster-Powell K \& Brand-Miller JC (2008) International tables of glycemic index and glycemic load values: 2008. Diabetes care 31, 2281-2283.

10. Sun L, Lee DE, Tan WJ, et al. (2015) Glycaemic index and glycaemic load of selected popular foods consumed in Southeast Asia. BrJ Nutr 113, 843-848.

11. Yang Y-X, Wang H-W, Cui H-M, et al. (2006) Glycemic index of cereals and tubers produced in China. World J Gastroenterol 12, 3430-3433.

12. International Standards Organization (2010) Food Products Determination of the Glycaemic Index (GI) and Recommendation for Food Classification. ISO 26642:2010. Switzerland: ISO.

13. Brouns F, Brouns F, Bjorck I, et al. (2005) Glycaemic index methodology. Nutr Res Rev 18, 145-171.
14. Korea Health Industry Development Institute (2013) National Health Statistics 2012: Korea National Health and Nutrition Examination Survey (KNHANESV-3). Osong: KHIDI.

15. Rural Development Administration National Academy of Agricultural Science (2011) Food Composition Table, 8th ed. Suwon: Rural Development Administration.

16. Rural Development Administration National Academy of Agricultural Science (2009) Food Composition and Nutrition Table, 1st ed. Suwon: Rural Development Administration.

17. The Korean Dietetic Association (1999) Estimated Food Size by Eye Measurements of Food Photos. Seoul: The Korean Dietetic Association.

18. Korea Centers for Disease Control and Prevention, Korea National Institute of Health (2015) Food Photos for Quantity Estimation: Korean Genome and Epidemiology Study. Osong: Korea Centers for Disease Control and Prevention.

19. Foster-Powell K \& Miller JB (1995) International tables of glycemic index. Am J Clin Nutr 62, 871S-890S.

20. Sugiyama M, Tang A, Wakaki Y, et al. (2003) Glycemic index of single and mixed meal foods among common Japanese foods with white rice as a reference food. Eur J Clin Nutr 57, $743-752$.

21. Chillo S, Ranawana DV, Pratt M, et al. (2011) Glycemic response and glycemic index of semolina spaghetti enriched with barley beta-glucan. Nutrition 27, 653-658.

22. Thondre PS \& Henry CJ (2009) High-molecular-weight barley beta-glucan in chapatis (unleavened Indian flatbread) lowers glycemic index. Nutr Res 29, 480-486.

23. Kim J-C, Kim J-I, Kong B-W, et al. (2002) Postprandial glucose and insulin responses to processed rice products in normal subjects. Prev Nutr Food Sci 7, 174-178.

24. Rokka S, Ketoja E, Järvenpää E, et al. (2013) The glycaemic and C-peptide responses of foods rich in dietary fibre from oat, buckwheat and lingonberry. Int J Food Sci Nutr 64 , 528-534.

25. Shin D-H (2004) Korean Traditional Food: Status, Prospects and Vision for Globalization. Taipei: Food and Fertilizer Technology Center.

26. Cha J-A, Cha G-H, Chung L-N, et al. (2008) Investigation on the history of the muck (traditional starch jelly) and its processing methods reviewed in the ancient and the modern culinary literatures. Korean J Food Culture 23, 73-89.

27. Collier G, McLean A \& O'Dea K (1984) Effect of co-ingestion of fat on the metabolic responses to slowly and rapidly absorbed carbohydrates. Diabetologia 2, 50-54.

28. Lutsey PL, Steffen LM \& Stevens J (2008) Dietary intake and the development of the metabolic syndrome: the Atherosclerosis Risk in Communities study. Circulation 117, 754-761.

29. Nara K, Yamaguchi A, Maeda N, et al. (2009) Antioxidative activity of water soluble polysaccharide in pumpkin fruits (Cucurbita maxima Duchesne). Biosci Biotechnol Biochem 73, 1416-1418.

30. Kim DY, Lee H, Choi EY, et al. (2015) Analysis and evaluation of glycemic indices and glycemic loads of frequently consumed carbohydrate-rich snacks according to variety and cooking method. J Korean Soc Food Sci Nutr 44, 14-23. 